\title{
DE LODEN CHINESE OFFERVATEN VAN DE FAMILIE PHILIPS
}

\section{Rituele wijnkan, 'jia’ (afb.1)}

Een buikige drievoet met een halfronde greep en wijd uitlopende mond. Aan weerszijden van de bovenrand verrijzen twee korte standers, elk bekroond met een omgekeerd bekervormige knop. De drie lobben van de kan zijn - simpel, maar voor de 'definiëring' van de vorm zeer effectief gedecoreerd met drie chevrons, gevormd door een rondom op-en-neer doorgaande dubbele lijn in dun draadreliëf. Rond de hals, evenals rond de knoppen op de standers lopen smalle reliëfbandjes van een in de late Shang en vroege Zhou gebruikelijk patroon: een symmetrisch verdeelde afwisseling van 'ogen' met gestyleerde 'vleugelpennen'.

\section{Ritueel wijnvat, 'you' (afb. 2)}

Een relatief gedrongen vat, ovaal in doorsnede, met relatief hoog, bol deksel, ${ }^{2}$ daar bovenop een kegelvormige knop. Op het breedste punt van de schouders bevindt zich aan weerszijden een half oog waar een hengsel los draaiend aan bevestigd is. ${ }^{3}$ Rond de schouders loopt ter hoogte van de hengselaanzet een reliëfband van sterk gestileerde lineaire 'draken' tegen een achtergrond van leiwen-spiralen, met in het midden aan beide zijden een gehoornde runderkop. Het deksel heeft recht daarboven twee identieke kopjes in een iets kleinere versie, slechts verbonden door een dubbele lijn in draadreliëf, en aan weerszijden, boven de hengsel-ogen, steken daar twee gewoonlijk als 'vogelsnavels' geïnterpreteerde, opwippende punten uit. De voetring vertoont twee zware ribbels, vergelijkbaar met de decoratie op de bronzen gui van afb. 1 op p. 60.

\section{De schenkers}

De jia en you zijn een geschenk van de heer en mevrouw A.F. Philips-de Jongh aan de Vereniging, uit 1946. Anton Philips (1874-1951) was liddonateur van de Vereniging sinds de oprichting in 1918, en bestuurslid sinds $1945 .{ }^{4} \mathrm{Hij}$ was een fervent verzamelaar op uiteenlopende gebieden, van Hollandse Meesters tot zilver, porselein en Aziatische kunstvoorwerpen. En dat hij al doende ook zeker een ter zake kundig verzamelaar geworden was, moge blijken uit de bruiklenen uit zijn collectie die van tijd tot tijd in belangrijke tentoonstellingen in het buitenland hebben gefigureerd. ${ }^{5}$ Tijdens de Tweede Wereldoorlog heeft de Vereniging nog een bescheiden rol kunnen spelen in het behoud van de collectie Philips. De schilderijen gingen in zestig genummerde containers naar Den Haag, en verdwenen in de kluizen van de Nederlandse Handel Maatschappij, maar een tweede zending zaan :36:36AM kisten - met de kunstvoorwerpen - werd door het Amsterdamse Museuri vancess 


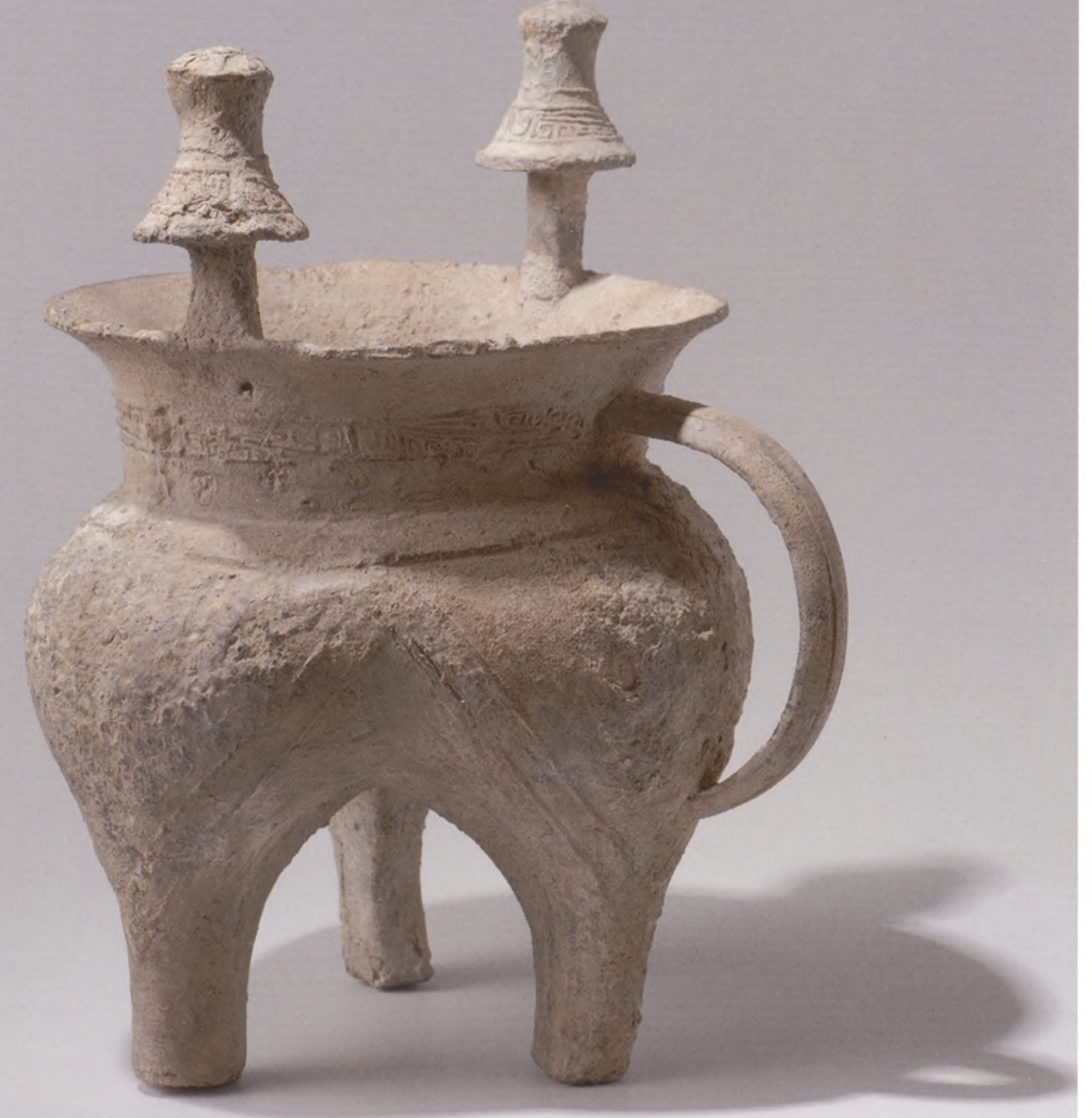

Afbeelding 1 Rituele wijnkan, jia, lood $(95,4 \%)$ en antimonium (4,6\%), hoogte $24 \mathrm{~cm}$., China, vroege Westelijke Zhouperiode, ca. $11^{e}$ eeuw v.Chr. Geschonken door de heer en mevrouw A.F. Philips-de Jongh in 1946, Rijksmuseum Amsterdam, collectie VVAK, MAK-5
Aziatische Kunst ondergebracht in hun bomvrije bergplaats bij Zandvoort (van waar ze begin januari 1945 weer ongedeerd op transport naar het zuiden gingen en in Eindhoven konden worden 'aangereikt'). ${ }^{6}$

De twee loden stukken waren gekocht bij de liquidatieveiling van het New Yorkse filiaal van het huis Yamanaka, in 1943. Volgens dr. Philips werden ze verkocht als zijnde tin, pewter, door de gevolmachtigde van de antiquairs ('een vakman', naar zijn mening). En gezien de ongebruikelijkheid van dat materiaal voor Chinees ritueel vaatwerk leek het hem interessant om nu juist deze voor het Museum te bestemmen. ${ }^{7}$

'Gebruikelijk' materiaal voor Chinees ritueel vaatwerk was uiteraard: brons een legering van koper met tin, en in het Chinese geval ook een beetje lood. Echter, het materiaal van deze vaten bleek geen tin te zijn maar hoofdzake lijk de andere toevoeging (aan koper) van Chinees brons: lood. Nògongebraí-ess 


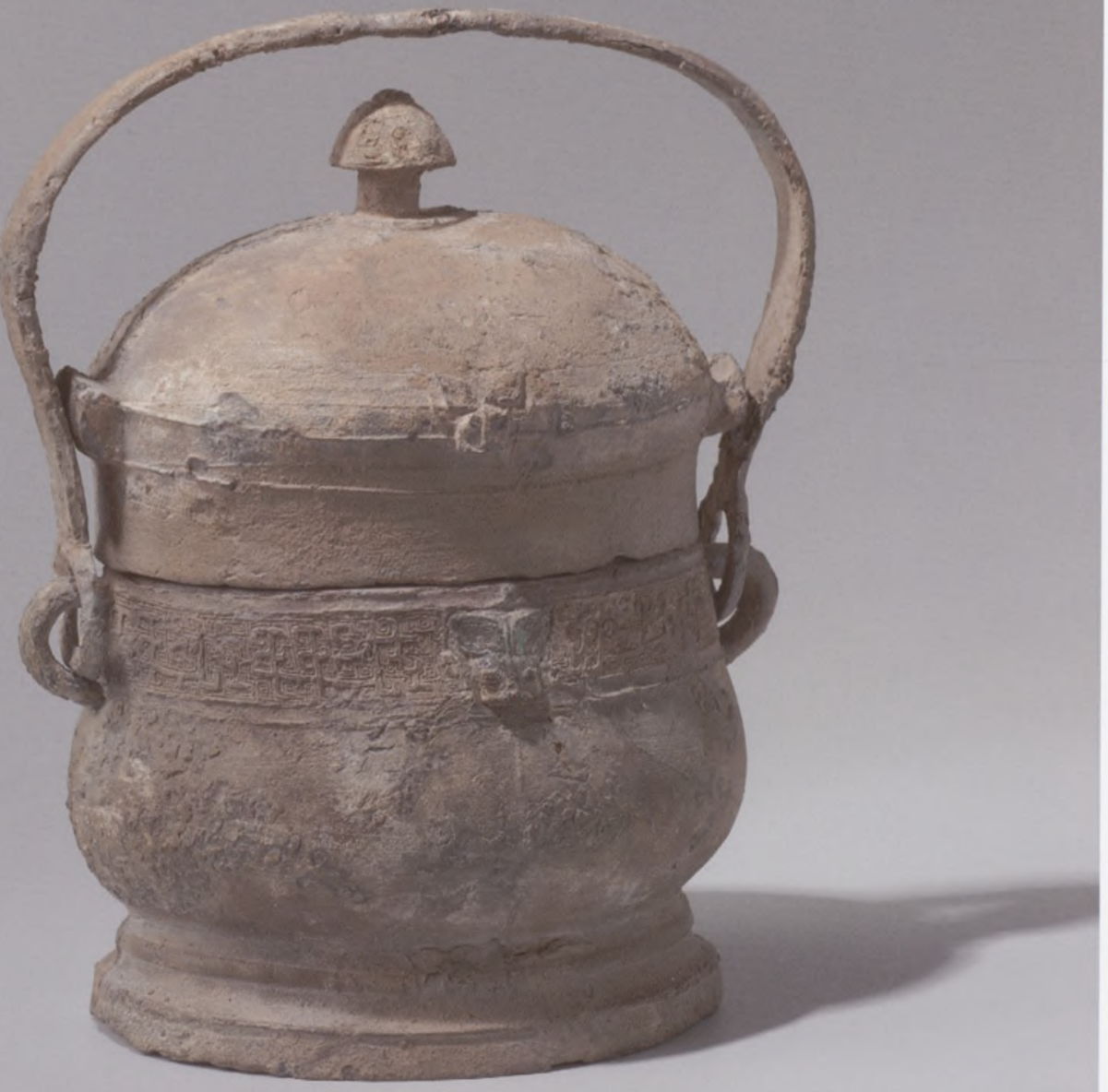

Afbeelding 2 Ritueel wijnvat, you, lood $(95,4 \%)$ en antimonium (4,6\%), hoogte $21 \mathrm{~cm}$., China, vroege Westelijke Zhouperiode, ca. $11^{e}$ eeuw v.Chr. Geschonken door de heer en mevrouw A.F. Philips-de Jongh in 1946, Rijksmuseum Amsterdam, collectie WAK, MAK-7 kelijker dus? Misschien, maar niet geheel ongehoord. De Yamanakacatalogus vermeldde al dat de jia en you in 1936 'samen met een aantal andere loden stukken' ergens in China waren opgegraven, en Jan Fontein, destijds conservator van het Museum voor Aziatische Kunst (in het Rijksmuseum) trof in een Chinees archeologisch tijdschrift afbeeldingen aan van loden vaatwerk, in een wetenschappelijk rapport over graven in de omgeving van de oude hoofdstad Luoyang, in Noord-China, (onder andere ook een zeer vergelijkbare jia en you, uit de vroege Zhou-periode). ${ }^{8}$

Als reden voor het gieten van offergerei in lood wordt meestal gesuggereerd dat het om een goedkoop surrogaat zou gaan, in tijden van oorlog en schaarste, of ook wel dat het proefgietingen zijn - om de keramische gietvorm te testen, moeten we dan aannemen. Dat laatste is niet onvoorstelbaar, $03: 36: 36 \mathrm{Am}$ aangezien lood zeer gemakkelijk 'vloeit' - maar of dat ook geldt voor het ee access 
lossen van het eindproduct, en over hoe dat zich dan weer verhoudt tot het eenmalig of hergebruik van de vormen ${ }^{9}$ - daarover zijn bij mijn weten nooit uitspraken gedaan. Pier Terwen, die de you nader heeft bestudeerd voor een behandeling in het restauratieatelier, achtte het in dit geval uitgesloten, vanwege de slordige afwerking van het product, en het feit dat het loden vat juist een duidelijke breuk in een van de delen van de mal laat zien. ${ }^{10}$ Een zeer recent onderzoek, door medewerkers van het Provinciaal Museum van Hubei in samenwerking met de universiteit van Wuhan, was speciaal gericht op de morfologie en functie van het loodgehalte in Chinees brons. De onderzochte bronsfragmenten kwamen uit verschillende graven van de Oostelijke (latere) Zhou-periode (770-221 v.Chr.) in Midden-China, en waren afkomstig van wapens zowel als rituele drievoet voedselvaten, ding. Naast ook weer de economische redenen voor een hoog percentage lood, opperen zij dat bij dergelijke vaten een groter gewicht wellicht het cruciale punt zou kunnen zijn. Het zou het 'gewicht', dat wil zeggen de macht en status kunnen symboliseren van de heer in wiens opdracht het vat vervaardigd was. ${ }^{11}$ Hier moet echter bij vermeld worden dat met een hoog loodgehalte in dit onderzoek bedoeld werd: een gewichtspercentage van meer dan $20 \%$. Het hoogst aangetroffen gehalte was $36 \%$, en 'onze' jia en you, met meer dan $95 \%$ bijna zuiver lood, mogen dan misschien niet de welhaast unieke zeldzaamheden zijn waar ze aanvankelijk voor werden aangezien, maar blijken ook hier dus toch weer ruimschoots 'hors concours, hors categorie'.

De 'gewone' Chinese (bronzen) offervaten uit de collectie Philips zijn in 1978 door de nazaten voor het merendeel in Londen geveild.

\section{Noten}

1. Eerder besproken in o.a.: H.F.E.Visser, Phoenix 1/5 (1946), p.2; id. 1/10 (1946), pp. 27-28; J. Fontein, 'Loden Vaatwerk uit de Chou periode', Bulletin VVAK. Derde Serie, nr. 9 (1957), pp. 144-8; Catalogus, Museum van Aziatische Kunst, z.pl., z.jr., nrs. 5 en 7; P. Lunsingh Scheurleer (red.), Asiatic Art in the Rijksmuseum. Amsterdam, Amsterdam, 1985, nrs. 4 en 5. Met dank aan Jan van Campen voor het archiefmateriaal.

2. Een ander (vroeger) type you is aanmerkelijk langgerekter en heeft in verhouding een kleiner deksel.

3. Bij de hogere you uit de late Shang (ca. 1300-1050 v.Chr.) is dit juist andersom, en verbindt het hengsel het midden van de 'lange' zijden van het ovaal.

4. Zie ook het inleidende artikel van Renée Steenbergen aan het begin van dit nummer.

5. Veilingcatalogus Christie's Amsterdam, 6-11-2007.

6. Archief VVAK, inv.nr. 62, Brief van H.F.E. Visser aan dr. A.F. Philips, d.d. 31-121945.

7. Archief VVAK, inv.nr.62, Brief van dr. A.F. Philips aan H.F.E. Visser, d.d. 2-4-1946.

8. Kaogu Tongxin 1 (1956), pl. 8. Vermeld en afgebeeld in J. Fontein, Op.cit. (noot 1) fig. 2.

9. Zie hierbij ook de beschrijving van de giettechniek (in eenmalige gietvormen) in de Shang en vroege Zhou, in het essay bij de tentoonstelling van bronzen uit het museum van Shanghai in Groningen, door Oliver Moore. Verkort weergegeven in Aziatische Kunst 38/1 (2008), p. 28.

10. P.A. Tenwen, 'Een Loden Yu Gerestaureerd', Mededelingenblad VVAK 10/5 (1980), pp. 3-7.

11. C. Pan, L. Liao, Y. Hu, 'Morphology of Metal Lead Addition to Ancient Chinese Bronzes', Advanced Materials Research 26-28 (2007), pp. 523-526. 